\title{
Should medical humanities be a part of the undergraduate medical curriculum?
}

\author{
Md. Anwarul Azim Majumder
}

Lecturer, Department of Clinical Sciences, School of Medical Sciences, University of Bradford, West Yorkshire, Bradford, UK

As medical practice throughout the world has become increasingly commercialised, it is suggested that inclusion of humanities in medical education may help to inculcate professionalism and moral qualities in students. ${ }^{1,2}$ The discipline of medical humanities $(\mathrm{MH})$ undertakes 'a sustained interdisciplinary enquiry into aspects of medical practice, education and research expressly concerned with the human side of medicine', ${ }^{3}$ which include diverse disciplines such as 'literature, art, creative writing, drama, film, music, philosophy, ethical decision-making, anthropology and history in pursuit of medical educational goals'. $\mathrm{MH}$ aim to 'search for connections between medical practice and the realities of our world' and enrich 'the mind and the soul' by challenging existing knowledge, imagination and feelings of tomorrow's doctors. ${ }^{1}$ $\mathrm{MH}$ help to improve 'the moral and personal development of physicians in training' and cultivate or maintain 'empathy during medical training'. ${ }^{2} \mathrm{MH}$ are designed to overcome the separation of clinical care from the 'human sciences' and foster interdisciplinary teaching and research to optimise patient care. $\mathrm{MH}$ have become part of the mainstream in medical education and are increasingly integrated into the basic medical curriculum in many developed countries. However, the discipline is an 'alien species' in Asia and teaching $\mathrm{MH}$ in medical school is now in 'prenatal stage' of its life. ${ }^{1,5-7}$ Educators and policymakers should seek for right approach to integrate the subject in the overcrowded medical curriculum. ${ }^{7,8}$

The purpose of medical education is to prepare competent physicians. It has increasingly been felt that the present doctors lack empathy and compassion when they interact with their patient. Today medical students are taught a great deal of biomedical sciences, 'but very little about the practice of medicine' and as a result 'they are too scientific and do not know how to take care of patients'. The essential humanitarian instincts of medical profession do not receive due attention in medical training and physicians fail to relate humanity in their professional life when they encounter patients. We need open-minded doctors who are able to better relate to their patients or understand their concerns. Students should be trained to conceptualize patient as a whole, rather than to focus on symptom only and treat people in a holistic way rather than the diseases only. Studying humanities may offer many benefits, including enhancing medical students' ability to communicate with patients or improve their comfort level in the clinical setting, consider the health in wider socio-economic contexts, and utilize more diverse ways of promoting well being and reducing the impact of ill-ness or disability. Various reports highlighted the role of medical humanities in training medical students. ${ }^{10,11}$

The MH programs in medical schools worldwide use various methods and approaches to make teaching effective and interesting, which include interactive small group learning, creative projects to allow students to reflect on patients and themselves, reading sessions in the weekends, monthly dinner meeting, photographic exhibits, reader's theatre, plays, dance, musical performances etc. ${ }^{7}$ Reported evidence of teaching $\mathrm{MH}$ is scarce in the medical schools of Asia. In Nepal, a voluntary module was taught at Manipal Col-lege of Medical Sciences, Pokhara ${ }^{5}$ and currently KIST Medical College (KISTMC), Lalitpur, Nepal is running a module for first year students. ${ }^{6}$ In the Melaka Manipal College of Medicine in Malaysia, students use patient narratives during the clinical years of training. ${ }^{12}$ A Medical Humanities Group was established in University College of Medical Sciences, Delhi, India with an aim to develop the discipline and increase practice amongst health care providers and organized in-teractive lectures by prominent personalities, art exhibition by the teachers, and street play by the medical students. ${ }^{13}$ The Faculty of Medicine, University of Ruhuna, Sri Lanka introduced an optional $\mathrm{MH}$ course for $4^{\text {th }}$ year medical students which included lectures with 'simple assessment'. 14

Educational innovations and experiments in medical schools are not common in Asia as seen in other parts of the world. ${ }^{15}$ Most of the medical schools in Asia have traditional, teacher-centred and hospital-based training. ${ }^{16,17}$ To produce 'humane' doctors for the community, medical schools need to review their mechanistic curricula and adopt various approaches to train students e.g. introduction of core curriculum and options, promotion of interdisciplinary learning and teaching, collaboration with arts and sociology disciplines, implementation of problem-based learning and community-based teaching, linkage with international institutes and organizations etc.

Correspondence: Dr. Md. Anwarul Azim Majumder, Lecturer, Department of Clinical Sciences, School of Medical Sciences, University of Bradford, Bradford BD7 1DP, West Yorkshire, UK. E-mail: a.a.majumder@bradford.ac.uk. 


\section{References}

1. Ramaswamy R.Embracing the unknown: introducing medical humanities into the undergraduate medical curriculum in India. Indian $\mathrm{J} \mathrm{Med}$ Ethics 2012 Jul-Sep;9:174-6.

2. Wershof Schwartz A, Abramson JS, Wojnowich I, Accordino R, Ronan EJ, Rifkin MR. Evaluating the impact of the humanities in medical education. Mt Sinai J Med 2009;76:372-80.

3. Evans M, Arnott R, Bolton G, et al. The medical humanities as a field of enquiry. Statement from the Association for Medical Humanities. $J$ Med Ethics 2001;27:104-5.

4. Kirklin, D. The Centre for Medical Humanities, Royal Free and University College Medical School, London, England. Academic Medicine 2003;78: 1048-53.

5. Shankar PR. A voluntary medical humanities module at the Manipal College of Medical Sciences, Pokhara, Nepal. Fam Med. 2008;40:46870.

6. Shankar R, Piryani RM. Three years of medical humanities at a new Nepalese medical school. Educ Health (Abingdon). 2011; 24:535.

7. Shankar PR. Can Medical Humanities take root in Asia? J Clin Diagn Res 2008Apr;2:791-5.

8. V J Grant. Making room for medical humanities. J Med Ethics: Medical Humanities 2002;28:45-8

9. Peabody F. The care of the patient. JAMA 1927; 88:877.
10. General Medical Council. Tomorrow's doctors. Recommendations on undergraduate medical education. London: General Medical Council, 1993.

11. Muller S (Chair). Physicians for the twenty-first century: report of the project panel of the General Professional Education of the Physician and College Preparation for Medicine. J Med Educ 1984;59 (11Pt2).

12. Biswas R, Dhakal B, Dhakal GR, Das RN, Nagra JS. Medical student narratives for understanding Disease and social order in the third world. Eubios $\mathrm{Jl}$ Asian Intl Bioethics (Tokyo) 2003;13:139-42.

13. Gupta R, Singh S, Kotru M. Reaching people through medical humanities: an initiative. $J$ Educ Eval Health Prof 2011;8:5.

14. Anoja Fernando. Teaching ethics and medical humanities to medical students in Sri Lanka: A multi-cultural approach. $8^{\text {th }}$ Bioethics Conference, Bangkok, Thailand, 19-23 March 2007.

15. Majumder MAA. Issues and Priorities of Medical Education Research in Asia. Ann Acad Med Singapore 2004;33:257-63.

16. Majumder MAA. 2002. A review of undergraduate medical curriculum. Bangladesh Med J 34:47-50.

17. Majumder MAA, Souza U, Rahman S. 2004. Trends in medical education: challenges and directions for need-based reforms of medical training in Southeast Asia. Indian $J$ Med Sci $58: 369-80$ 